remission even using biological therapy. DNAse activity of the blood serum and antinuclear antibody may be useful in this context. Changes of serum DNase activity in the RA treatment by biological agents previously have been not investigated.

Objectives: The aim of this work is to study the dynamics clinical and laboratory parameters, DNAse serum activity and ANA during the RA treatment by infliximab (INF) and assess the prognostic potential of them in prediction of response to INF. Methods: 24 RA patients were involved in the study. All patients fulfilled the EULAR/ACR 2010 RA criteria. 22/24 patients received 6 infusions of INF at a dose of $3 \mathrm{mg} / \mathrm{kg}$ according to standard protocol: at 0th, 2th, 6th and then every 8 week. 2/24 patient received 4 infusions of INF. All patients received synthetic DMARDs therapy by metotrexate (10-17,5 mg weekly), $18 / 24$ patients received glucocorticoids (methylprednisolone $4-8 \mathrm{mg}$ daily) and non-steroidal anti-inflammatory drugs. Prior to treatment by INF patients did not receive any biological agents. All patients had high disease activity before INF treatment (DAS28<5,1).

ANA determination was performed by indirect immunofluorescence on Hep-2 cells using digital system AKLIDES. ANA was measured in serum samples before 1st INF administration, at 22-30 weeks after the 1st INF administration.

To determine the DNAse activity of serum the method of rivanol clot was used. DNase activity was measured in serum samples before 1st INF administration, at 6 weeks after the 1 st INF administration, at 30 week of treatment.

Results: At week 30, ACR70 improvement reached 5/22 of the patients, ACR50 - 10/22 of the patients, ACR20 - 4/24 of patients.

At 30 weeks of treatment by INF $2 / 22$ of patients achieved remission $(\operatorname{SDAl}<3,3)$, $10 / 22$ - a low disease activity $(3,3<$ SDAl $\leq 11)$.

13/24 patients were ANA-positive before INF treatment, 12/22 - after 24 weeks of treatment.

Levels of serum DNase activity did not differ before and during the INF treatment $(p>0,05)$.

For assessment prognostic value of laboratory signs for INF response prediction logistic regression was used. Prognostic model, which included changes in ANA $(\triangle \mathrm{ANA})$ and DNAse serum activity level ( $\triangle \mathrm{DNAse}$ serum activity), anti-CCP- and RF-negativity was better $(p=0,02)$ (area under ROC-curve $=1,0 ; 95 \% \mathrm{Cl} 0,844-$ $1,00 \mathrm{p}=0,0001$ ) than the model, which included only anti-CCP- and RF-negativity (area under ROC-curve $=0,795 ; 95 \% \mathrm{Cl} 0,597-0,924, \mathrm{p}=0,0141$ ).

Conclusions: The study confirmed the efficacy of RA treatment by INF for anti-CCP and RF negative patients. DNAse serum activity and ANA may be used as additional prognostic biomarker of INF response. For the assessment DNAse activity as marker of response to therapy is needed futher investigations with more number of patients.

Disclosure of Interest: None declared

DOI: 10.1136/annrheumdis-2017-eular.6941

\section{SAT0167 CAN INFLIXIMAB EFFICACY BE PREDICTED BASED ON BLOOD CONCENTRATION AT THE FOURTH DOSE?}

M. Sato ${ }^{1}$, M. Takemura ${ }^{2}$, T. Tani ${ }^{1}$, T. Ohashi ${ }^{1} .{ }^{1}$ Rheumatology, Ohashi and Tani Orthopedics, Gifu; ${ }^{2}$ Advanced Diagnostic System Research Laboratory, Fujita Health University Graduate School of Health Sciences, Toyoake, Japan

Background: Biological drugs exhibit excellent efficacy and continuity in the treatment of rheumatoid arthritis (RA) and play an important role in RA treatment. Blood concentration is an important factor in the efficacy of biological drugs, particularly antibody drugs. Infliximab (IFX) is an antibody drug against TNF- $\alpha$ and is reported to require a blood concentration of $\geq 1 \mu \mathrm{g} / \mathrm{mL}$ to be effective.

Objectives: To investigate whether clinical efficacy can be predicted based on blood concentrations at the fourth dose of IFX in patients with RA.

Methods: This study included 56 patients with RA who were treated with IFX. Patients included 13 men and 43 women aged from 26 to 81 years (mean, 60.3 years). The IFX concentration was measured immediately before administering the fourth IFX dose (8 weeks after administering the third dose). We then investigated the relationship between subsequent IFX efficacy and IFX concentration immediately before the fourth dose of IFX in these patients with RA. Concentrations were measured in stored frozen serum by using the ELISA method.

Results: The IFX concentration immediately before the fourth dose was $>1$ $\mu \mathrm{g} / \mathrm{mL}$ in 32 patients $(\geq 1 \mu \mathrm{g} / \mathrm{mL}$ group $)$ and $<1 \mu \mathrm{g} / \mathrm{mL}$ in 24 patients $(<1$ $\mu \mathrm{g} / \mathrm{mL}$ group). At the fourth dose, IFX was effective in 30 patients $(93.8 \%)$ in the $\geq 1 \mu \mathrm{g} / \mathrm{mL}$ group, at a mean concentration of $5.18 \mu \mathrm{g} / \mathrm{mL}$, while the mean concentration was $5.69 \mu \mathrm{g} / \mathrm{mL}$ for the remaining 2 non-responders. IFX was also effective in 21 patients $(87.5 \%)$ in the $<1 \mu \mathrm{g} / \mathrm{mL}$ group but did not elicit any response in the other 3 patients. At this point, all 5 non-responsive patients were primary non-responders. Of all 51 responders, $58.8 \%$ were in the $\geq 1 \mu \mathrm{g} / \mathrm{mL}$ group and $41.2 \%$ were in the $<1 \mu \mathrm{g} / \mathrm{mL}$ group. Based on the data, we observed no relationship between efficacy and IFX concentration. After 1 year of IFX treatment, 36 of the 56 patients were responsive and 20 were non-responsive. In the 2 groups, 26 responsive patients $(63.9 \%)$ and 9 non-responsive patients (45.0\%) had an IFX concentration of $\geq 1 \mu \mathrm{g} / \mathrm{mL}$ immediately before the fourth dose.

Conclusions: At the fourth dose, many of the patients with an IFX concentration of $<1 \mu \mathrm{g} / \mathrm{mL}$ were also responsive to the treatment, so future efficacy was difficult to predict based on IFX concentration. In other words, during clinical evaluation, measurement of IFX concentrations is not necessary in responsive patients. However, IFX concentrations should be measured in non-responsive patients or patients with a diminished response. If the concentration is $<1$ $\mu \mathrm{g} / \mathrm{mL}$, IFX efficacy should be restored by increasing the dose or shortening the administration interval.

Disclosure of Interest: None declared

DOI: 10.1136/annrheumdis-2017-eular.6072

\section{SAT0168 DISCONTINUATION OF FIRST BIOLOGIC THERAPY IN RHEUMATOID ARTHRITIS: MAIN CAUSES AND CORRELATION BETWEEN SECONDARY INEFFICACY AND DEVELOPMENT OF IMMUNOGENICITY}

P. Bogas $^{1}$, C. Plasencia ${ }^{1}$, D. Pascual-Salcedo ${ }^{2}$, G. Bonilla ${ }^{1}$, E. Moral ${ }^{1}$,

C. Tornero ${ }^{1}$, L. Nuño ${ }^{1}$, A. Villalba ${ }^{1}$, D. Peiteado ${ }^{1}$, A. Martinez $^{2}$, B. Hernandez ${ }^{2}$ A. Balsa ${ }^{1} .{ }^{1}$ Rheumatology; ${ }^{2}$ Immunology, Hospital Universitario la Paz, Madrid, Spain

Background: Biologic therapy has been a major change in Rheumatoid Arthritis (RA) prognosis, but around $40 \%$ of patients (pts) fail to respond. Part of this treatment failure can be explained by the development of anti-drug antibodies (ADA), but the ADA-associated secondary inefficacies rate is currently unclear Objectives: To assess in our AR cohort treated with Adalimumab (Ada), Infliximab (Ifx), etanercept (Etn), certolizumab (Czp), Tocilizumab (Tcz) and Abatacept (Abt) as 1st biologic agent, the frequency of drug suspension as well as the main causes for discontinuation and the secondary inefficacy rate associated with the development of immunogenicity

Methods: From the RA cohort that initiated their 1st biologic agent at Hospital La Paz between 2005 and 2016, only those who had suspended those drugs were included, and causes for suspension were collected. Clinical activity was measured by DAS28 and Delta-DAS28 at 6 months of treatment to classify discontinuation by primary or secondary inefficacy. Drug levels (DL) and/or ADA were also measured by ELISA at 6 months since initiating the biologic agent in 43 pts and at drug discontinuation in 59 pts. Primary inefficacy was defined as DAS28 $>3.2$ and delta-DAS28 $<1.2$ at 6 months with DL present. Secondary inefficacy was defined both as DAS28 $>3.2$ plus delta-DAS28 $<1.2$ at 6 months with ADA+ and Delta-DAS28 $>1.2$ or DAS28 $<3.2$ at 6 months with subsequent loss of efficacy. Statistical analysis was performed using SPSS version 20.0

Results: From the 246 pts who started their first biologic therapy, $144(58 \%)$ pts who had definitively discontinued were included. [lfx ( $\mathrm{n} 35,24 \%)$, Ada ( $\mathrm{n} 40,28 \%)$, Etn (n 30,21\%), Czp (n 23, 16\%), Tcz (n 10,7\%) y Abt (n 6, 4\%)]. $116(80,6 \%)$ were women. The mean age was $56.3 \pm 14.7$ years. The mean time of biologic was $2.23 \pm 1.96$ years. From the global cohort, $18(12.5 \%)$ drop out the treatment due to primary inefficacy, $41(28.5 \%)$ to secondary inefficacy, $57(39.6 \%)$ to adverse effects $(\mathrm{AE}), 11(7.6 \%)$ to remission and $17(11.8 \%)$ to other causes (surgery, pregnancy, etc.). $12.5 \%$ pts who discontinued due to AE or other causes had also a primary or secondary inefficacy; by including those pts in these last causes for suspension, a total of $20 \mathrm{pts}(14 \%)$ failed due to primary inefficacy and 57 pts $(39.6 \%)$ to secondary inefficacy. The most frequent AEs were: infections ( $35 \%)$, cutaneous AEs (psoriasis, rash, etc. (10.5\%), infusion reactions $(9 \%)$ and neoplasia (9\%). Of the 59 pts who had DL/ADA measured at drug discontinuation, $42.4 \%$ were ADA +. Within the group that failed due to secondary inefficacy and had DL/ADA determined, 50\% were ADA+; nevertheless this rate was smaller in suspensions due to other causes. Likewise, in the ADA+ pts, $73 \%$ suspended due to secondary inefficacy

\begin{tabular}{|l|c|}
\hline \multicolumn{2}{|c|}{ Demographic Characteristics } \\
\hline Age (years) & $64 \pm 15,4$ \\
\hline Sex (Female) & $116(80,6 \%)$ \\
\hline Smokers & $25(17,6 \%)$ \\
\hline BMC & $27,79 \pm 8,87$ \\
\hline Disease duration & $16,7 \pm 8,04$ \\
\hline RF + & $117(81,3 \%)$ \\
\hline Anti-CCP + & $119(85,6 \%)$ \\
\hline $\begin{array}{l}\text { Duration of treatment } \\
\text { (years) }\end{array}$ & $2,23 \pm 1,96$ \\
\hline Basal DMARDs & $127(89 \%)$ \\
\hline Basal Methotrexate & $82(57,3 \%)$ \\
\hline Basal Leflunomide & $57(39,6 \%)$ \\
\hline Basal Salazopyrine & $13(9,1 \%)$ \\
\hline Basal CPR & $15,14 \pm 19,4$ \\
\hline Basal ESR & $34,2 \pm 23,4$ \\
\hline Basal DAS & $5,24 \pm 1,32$ \\
\hline
\end{tabular}

Conclusions: In our RA cohort, adverse effects were the main cause for discontinuation, with infections at 1 st place. The 2 nd cause conditioning interruption was the secondary inefficacy, in which $50 \%$ of our pts were ADA+ at drug 